\title{
A IMPORTÂNCIA DA INTEGRAÇÃO ENTRE O SISTEMA DE GESTÃO ESCOLAR, AMBIENTE VIRTUAL DE APRENDIZAGEM E OS PORTAIS EDUCACIONAIS: UMA VISÃO DO DEPARTAMENTO REGIONAL SESI/SENAI DE GOIÁS
}

\author{
GOIÂNIA/GO JULHO/2018 \\ Cleiton Abadia Duarte - SENAI - cleitonabadia.senai@sistemafieg.org.br \\ Tipo: Relato de Experiência Inovadora (EI) \\ Categoria: Métodos e Tecnologias \\ Setor Educacional: EDUCAÇÃO MÉDIA E TECNOLÓGICA
}

\begin{abstract}
RESUMO
A preocupação com o aprimoramento do processo educacional na modalidade a distância frente ao avanço tecnológico está cada dia mais presente no contexto de formação e aprendizado do aluno. Este artigo objetiva a compreensão das potencialidades dos principais recursos presentes nesta modalidade de ensino e sua importância na atuação de forma integrada oportunizando a equipe de Tutores e Coordenadores, instrumentos de trabalho mais eficazes. Para tanto, se baseou em um modelo de atuação do Núcleo Integrado de Educação a Distância do SESI/SENAI - GO para apresentar uma visão geral do cenário tecnológico.
\end{abstract}

Palavras-chave: Tecnologia. Sistema de Gestão Escolar. Ambiente Virtual de Aprendizagem. 


\section{INTRODUÇÃO}

A educação a distância se apresenta em grande evolução principalmente pelo fato do avanço e atualização constante dos recursos tecnológicos. O crescente desenvolvimento das tecnologias imprime fatores positivos na educação e com benefícios para o caminho do processo de ensino e aprendizagem. Diante de vários recursos, promover a integração das ferramentas transmite para a modalidade a distância um cenário centrado e organizado com adequações pertinentes ao meio e formação dos alunos.

O envolvimento da tecnologia na educação e suas efetivas contribuições são perceptíveis no progresso educacional. As percepções mudam a cada novo recurso, a cada nova implementação, o que transmite a todos os envolvidos a positividade das ferramentas tecnológicas (FARIAS, 2013; VIEIRA, 2011).

Para Martins, Tiziotto e Cazarini, (2016); Oliveira, Cortimiglia e Longhi, (2015), no contexto e atuação da Educação a Distância, um recurso é essencial e deve ser tratado com cuidado ao ser disponibilizado aos alunos como forma de minimizar os espaços físicos e otimizar a construção do conhecimento que é o Ambiente Virtual de Aprendizagem. Outros ambientes também são utilizados por este público e também devem ser levados em consideração que são os portais educacionais. Com foco no elo de ligação entre esses recursos, se encontra o Sistema de Gestão que alimenta todo ciclo de execução.

Diante do cenário inovador, o presente artigo consiste na apresentação dos principais meios utilizados na Educação a Distância e um modelo de atuação integrada com base nos processos desenvolvidos pelo Departamento Regional de Goiás.

\section{OBJETIVOS}

Apresentar as principais características do Sistema de Gestão Escolar, do Ambiente Virtual de Aprendizagem e dos Portais Educacionais;

Descrever a importância de um ambiente tecnológico integrado.

\section{A presença da Tecnologia na Educação a Distância}

A sociedade vivencia um processo de atualização avançada principalmente no que diz respeito a tecnologia. Este cenário reflete a utilização de novos recursos e a 
necessidade do aprendizado contínuo, em função da adaptação ao conhecimento. $O$ mesmo acontece no meio educacional onde as formas de construção e difusão do conhecimento se faz cada vez mais presente frente ao modelo tecnológico no ensino e aprendizagem (VIEIRA, 2011).

Conforme Moran (2003), ao se falar em tecnologia, logo se pensa em computadores, softwares e internet, mas o conceito de tecnologia vai além das premissas e é muito mais abrangente. Na verdade são todos os meios, os apoios, as ferramentas utilizadas na aprendizagem dos alunos. A forma como se organizam os grupos, as salas de aula também é considerada tecnologia.

De acordo com Santos e Mantilla (2016), a Educação a Distância (EaD) é uma modalidade de ensino fortemente mediada pela utilização de tecnologias digitais da informação e comunicação. Diante desta questão, e com o avanço significativo desta modalidade, torna-se fundamental a implementação de ações de planejamento e elaboração de estratégias para adequação do modelo educacional.

As Novas Tecnologias da Informação e Comunicação (NITCs) oferecem possibilidades de interações mediatizadas com grande variedade e de excelente qualidade. Possibilita a flexibilidade da interação humana com a independência do tempo e principalmente do espaço (SILVA; CAMPOS, 2016).

Com auxílio da tecnologia e sua frequente utilização, várias mudanças podem ser observadas na $\mathrm{EaD}$ que podem ultrapassar os limites. $O$ crescimento da modalidade, a otimização dos recursos, a interação entre os atores, a garantia e confiabilidade das informações, a segurança e a disponibilidade são alguns exemplos do ganho expressivo do avanço tecnológico e sua inserção no contexto educacional (FARIAS, 2013).

\section{Sistema de Gestão Escolar}

Com foco na oferta de uma educação de qualidade, a gestão escolar deve ser o instrumento estratégico com objetivo de promover a eficácia nas atividades e a integração dos métodos de trabalho por meio da utilização de tecnologias confiáveis o que minimiza os erros pertinentes ao processo gerencial.

O objetivo maior da comunidade educacional revela-se, portanto, o de se estabelecer uma comunidade de ensino efetivo, onde persevere, coletivamente, não somente o ideal de ensinar de acordo com o saber produzido socialmente, mas o de aprender, em acordo com os princípios de contínua renovação do conhecimento, criandose um ambiente de contínuo desenvolvimento para alunos, professores, funcionários e é claro, os gestores (LUCK, 2009). 
O sistema de gestão escolar é um dos fatores fundamentais no processo de ensino e aprendizagem. Todo o gerenciamento e ações estão presentes em suas funcionalidades além de armazenar todos registros de cada execução. Este recurso armazena também todas as informações pertinentes a cursos (oferta; conclusão), alunos (cadastro; turmas), professores (cadastro; turmas) e gestores (toda ferramenta) além de permitir uma vasta configuração independente nos meios de oferta e entrega do produto.

Diante do objetivo de manter a praticidade e a comodidade, um estudo contínuo deve ser realizado e os levantamentos devem ser analisados em busca de novas implementações e adequações para garantir um produto que atenda a todas as necessidades com inteligência na execução de cada atividade. Vale ressaltar que o nível de gestão alcançado em um sistema parametrizado, não se compara a execução das tarefas de forma manual. Além de economizar tempo e ganhar em produtividade, reduz ao extremo os possíveis erros chamados de "erros humanos".

Uma boa ferramenta de gestão escolar deve apresentar como pontos principais: uma forma inteligente de captação de matrículas; o combate fiel a inadimplência; filtrar e minimizar os retrabalhos; organizar o processo financeiro e manter o foco na satisfação dos alunos.

\section{Ambiente Virtual de Aprendizagem}

Martins et al. (2016) relata que o advento dos recursos computacionais apresentou diversos desafios no contexto educacional, culminando no surgimento de novas teorias, modalidades e teorias de aprendizagem. Diante deste cenário, surge uma questão, o que vem a ser Ambiente Virtual de Aprendizagem?

Ainda para Martins et al. (2016), como resposta ao questionamento, possui como objetivo principal figurar um espaço de construção do conhecimento por meio do desenvolvimento de atividades educativas, diante da mediação da Tecnologia, valorizando a interação e o trabalho colaborativo.

Para Arbex e Bittencourt (2007), são cenários que envolvem interfaces instrucionais para interação da aprendizagem onde podem incluir várias ferramentas de forma autônoma e monitorada com recursos de aprendizagem coletiva e individual.

Já na visão de Dotta (2011), são recursos centrados em atividades e conteúdos prédeterminados pelo docente cujo o processo de aprendizagem é definido antecipadamente. 
Ribeiro, Mendonça e Mendonça (2007) descrevem que são softwares educacionais, destinados ao apoio a educação a distância. Oferecem um gama de tecnologias de informação e comunicação que permitem o desenvolvimento das atividades no tempo, espaço e ritmo de cada aluno.

Para Oliveira et al. (2015), são ambientes geralmente baseados em Web e são destinados ao gerenciamento eletrônico de cursos e atividades virtuais.

Vários autores apresentam definições diferenciadas sobre este assunto, mas é notório o envolvimento e a importância do Ambiente Virtual de Aprendizagem no processo de ensino e aprendizagem. É um rico aliado da Educação a Distância frente a competitividade atual e a formação de indivíduos para o mercado de trabalho.

Um ponto de grande importância e cuidado na disponibilização de um Ambiente Virtual de Aprendizagem aos estudantes, é a questão da estrutura visual, o layout, o formato em que são disponibilizados os conteúdos e atividades que se torna um diferencial na atuação dos atores, a satisfação e a positividade de aproveitamento dos estudos.

A informação apresentada na página deve ser organizada de forma a facilitar a sua visualização e interpretação correta. O propósito do design da página de um módulo educacional não é só apresentar a informação, mas também ajudar o estudante no seu processo de aprendizagem (ARBEX; BITTENCOURT, 2007).

Arbex e Bittencourt (2007) relatam ainda que o desenvolvimento de um ambiente virtual não é simplesmente traduzir aulas presenciais para uma plataforma a distância. Necessita de cuidados em seu planejamento e a topologia deve ser apresentada por um conjunto de articulações, estratégias e táticas pedagógicas.

Segundo Martins et al. (2016), de forma resumida, os Ambientes Virtuais fazem uso da internet para permitir o acesso aos conteúdos, armazenamento e disponibilização de documentos; a comunicação síncrona e assíncrona dos atores envolvidos; o gerenciamentos dos processos pedagógicos e administrativos; a produção e disponibilização de atividades e avaliações individuais ou em grupos; a aprendizagem adaptativa e em diversas modalidades, entre outros recursos.

\section{Portais Educacionais}

Por se tratar de um processo voltado a Educação a Distância, a presença dos portais educacionais é de extrema importância para que o ciclo de atividades seja satisfatória e com a qualidade ideal diante do cliente. 
A Internet é um espaço virtual de comunicação e de divulgação. Hoje é necessário que cada escola mostre sua cara para a sociedade, que diga o que está fazendo, os projetos que desenvolve, a filosofia pedagógica que segue, as atribuições e responsabilidades de cada um dentro da escola. É a divulgação para a sociedade toda. É uma informação aberta, com possibilidade de acesso para todos em torno de informações gerais (MORAN, 2003).

Diante deste cenário, torna-se fundamental o destaque a três portais (Divulgação e Matrícula; Financeiro e Portal do Aluno).

O portal de divulgação e matrícula pode ser considerado o canal de ingresso, a porta de entrada do aluno a todos os procedimentos que envolvem a utilização das ferramentas para aprendizagem a distância. É neste local que a instituição deve trabalhar no modelo atrativo de envolvimento e apresentação de todos os produtos, de todo portfólio disponibilizados para matrículas e também os que ainda estão fora do período de matrículas, com foco no registro de interesse. Os interessados precisam ter conhecimento de todas as informações pertinentes a cada curso com opor exemplo (Objetivo; conteúdo programático; forma de oferta; carga horária; pré-requisito; valor e formas de pagamento; escola ofertante), e desta forma decidir por ingressar ou não ao curso.

Já o portal financeiro deve ser um local para consultas e controle de pagamentos. Se apresenta como um grande aliado ao cliente principalmente para gerenciamento de cursos com valores parcelados, onde o mesmo deve conseguir gerar os pagamentos futuros e consultar os pagamentos já realizados além de ter a possibilidade de impressão dos comprovantes. Além disso, o ideal é que neste portal, o pagamento do aluno também possa ser realizado a distância, principalmente pela utilização do cartão de crédito.

O portal do aluno é de suma importância neste cenário, onde deve ser um ambiente disponibilizado pela instituição de ensino com objetivo de auxiliar o aluno nos processos educacionais e administrativos. O aluno deve conseguir visualizar as informações de todos os cursos além da opção de impressão dos certificados. O mesmo deve conseguir acesso aos contatos das escolas e também ao acervo da biblioteca virtual da instituição.

Em resumo, são ambientes em benefício da instituição e principalmente dos alunos durante todo processo de execução do curso e também posterior a sua conclusão.

\section{A Visão dos Processos Integrados entre o Sistema de Gestão Escolar, Ambiente Virtual de Aprendizagem e os Portais Educacionais}

Moran (2003) descreve a importância do funcionamento de todos os recursos de forma 
integrada, onde todo cenário estabelece uma comunicação harmoniosa e de confiabilidade perante as entregas e demandas educacionais e administrativas da instituição.

Para Silva e Campos (2016), a Educação a Distância tem sido vista como um grande fenômeno de inovação educacional diante das integrações das novas tecnologias como proposta de democratização do conhecimento e aprimoramento dos processos educacionais.

Diante de todo levantamento apresentado, uma visão macro do processo integrado pode ser apresentada da se seguinte forma:

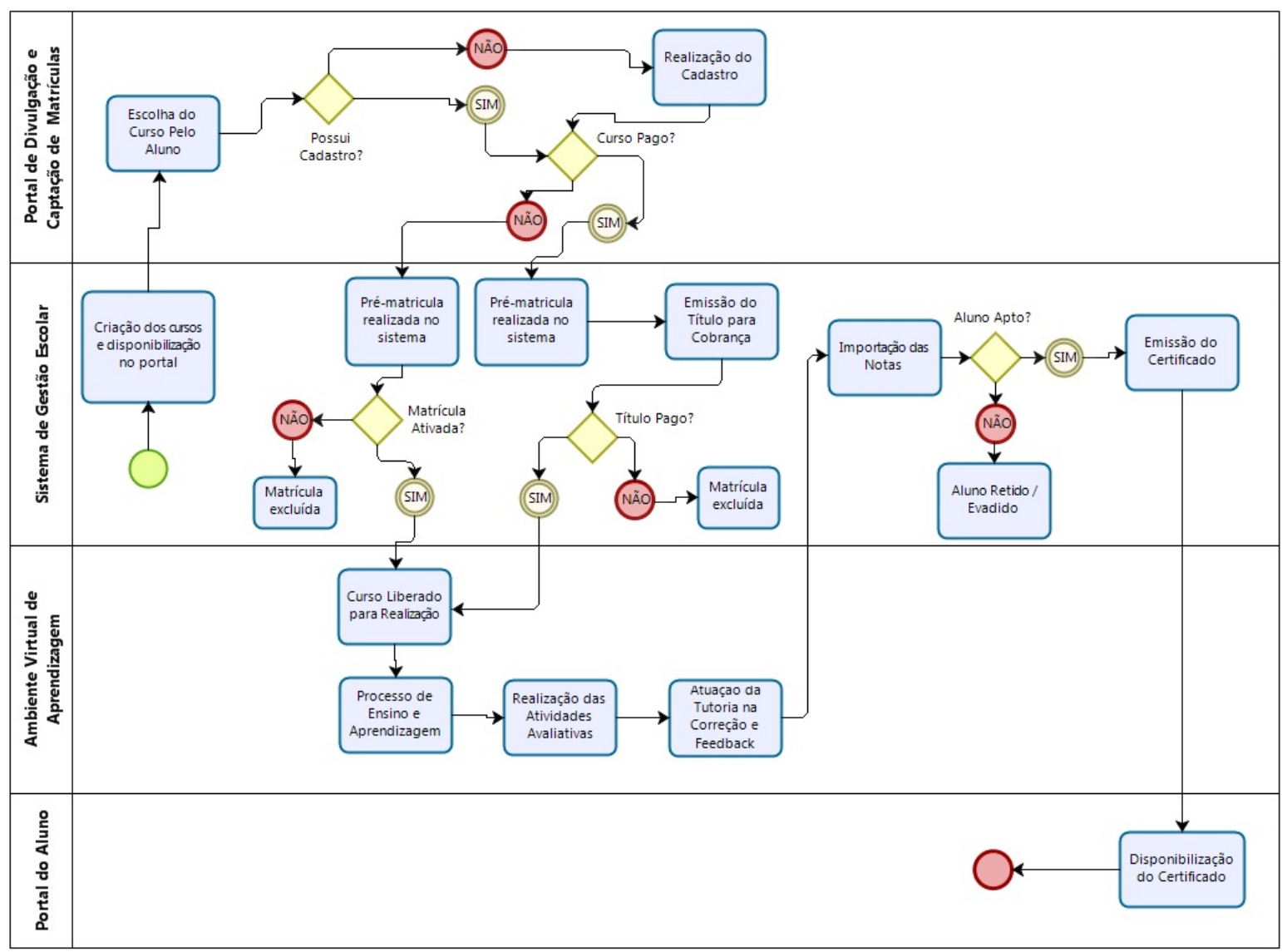

Figura 1: Fluxo do processo integrado no uso das ferramentas de matrícula, aula, pagamento e registro escolar.

Todo processo gira em torno do Sistema de Gestão Escolar, onde são criados os cursos para disponibilização no portal de divulgação e matrículas. As informações pertinentes aos cursos e períodos de matrícula e execução também são ajustados neste sistema de gestão. Após a liberação dos cursos, os interessados realizam as matrículas e novamente voltam para um processo de gerência neste cenário que permanece durante 
todo curso até a realização da certificação, onde o próprio sistema é responsável pela emissão e disponibilização no Portal do Aluno.

Para exemplificar melhor o modelo, pode-se destacar os seguintes pontos:

- A administração está totalmente integrada ao Sistema de Gestão Escolar;

- Os cursos são configurados no sistema e disponibilizados para matrículas no portal;

- Após a escolha no portal, os alunos entram no processo gerenciado e especificado exclusivamente para cada curso;

- Para cursos gratuitos, os alunos já estão pré-matriculados e aguardando apenas a ativação da matrícula diante de um e-mail encaminhado (Em caso de não ativação, após um período, a matrícula é excluída);

- Para cursos pagos, a pré-matrícula também é realizada e para formalização do processo, basta que o aluno pague o título gerado e se necessário, envie a documentação necessária a escola (Em caso de falta de pagamento, após um período, a matrícula é excluída);

- O próximo passo se dá ao ingresso do aluno ao Ambiente Virtual de Aprendizagem, onde se porta apenas como "Sala de Aula", sendo o local mediado pela tutoria com foco na aprendizagem do aluno;

- Após a conclusão da etapa anterior, o Sistema de Gestão Escolar deve importar as notas lançadas no Ambiente Virtual diretamente para sua gestão no curso;

- Com as notas já presentes em sua estrutura, o responsável pelo Sistema de Gestão realiza o processo de certificação e novamente a integração entra em ação disponibilizando o certificado para o aluno em seu portal.

A utilização do modelo apresentado se destaca pela praticidade, agilidade, confiabilidade e entrega de resultados, ou seja, ponto positivo para a instituição que se garante na competitividade do mercado atual e na satisfação do cliente que é o fator fundamental neste ambiente integrado de ensino.

\section{CONSIDERAÇÕES FINAIS}

A tecnologia se encontra fortemente presente em meio a educação a distância agregando valor a cada um dos processos. Os sistemas e ambientes por sua vez se apresentam fortemente em benefício dos atores envolvidos no ensino e aprendizagem, mesmo de forma individual e particular.

O ponto chave deste cenário está no trabalho integrado de cada uma das ferramentas. A 
junção das forças, o trabalho harmonioso e a compreensão das funcionalidades transmitem a positividade da integração e potencializam as ações de uma forma geral.

Surge então a importância desta integração principalmente no ensino a distância, pois otimiza e transmite para os atores internos a segurança no gerenciamento das atividades e transparece ao cliente, neste caso, o aluno um modelo de atuação organizada com foco em uma formação de qualidade e com a certeza da preparação ideal para o competitividade frente ao mercado atual.

\section{REFERÊNCIAS}

ARBEX, D. F.; BITTENCOURT, D. F. DE. Estratégias para o Desenvolvimento de um Ambiente Virtual de Aprendizagem: Um Estudo de Caso Realizado na UNISUL Virtual. Associação Brasileira de Educação a Distância, p. 1-7, 2007.

DOTTA, S. Uso de uma Mídia Social como Ambiente Virtual de Aprendizagem. Anais do XXII SBIE - XVII WIE, p. 610-619, 2011.

FARIAS, S. C. Os Benefícios das Tecnologias da Informação e Comunicação (TIC) no Processo de Educação a Distância (EaD). Revista Digital de Biblioteconomia e Ciência da Informação - RDBCI, p. 15-29, 2013.

LUCK, H. Dimensões da Gestão Escolar e suas Competências. Editora Positivo. ISBN 978-85-385-0027-8. Curitiba: [s.n.], 2009.

MARTINS, D. DE O.; TIZIOTTO, S. A.; CAZARINI, E. W. Ambientes Virtuais de Aprendizagem (AVAs) Como Ferramentas de Apoio em Ambientes Complexos de Aprendizagem (ACAs). Revista Brasileira de Aprendizem Aberta e a Distância, v. 15, 2016.

MORAN, J. Gestão Inovadora da Escola com Tecnologias. Texto publicado em VIEIRA, Alexandre (org.). Gestão educacional e tecnologia. São Paulo, Avercamp, 2003. Páginas 151-164., p. 151-164, 2003.

OLIVEIRA, D. T. DE; CORTIMIGLIA, M. N.; LONGHI, M. T. Ambientes Virtuais de Aprendizagem no Ensino Superior Presencial : O Processo de Adoção da Tecnologia na Perspectiva do Docente. Revista Brasileira de Aprendizagem Aberta e a Distância, v. 14, p. 153-176, 2015. 
RIBEIRO, E. N.; MENDONÇA, G. A. DE A.; MENDONÇA, A. F. DE. A Importância dos Ambientes Virtuais de Aprendizagem na Busca de Novos Domínios da Ead. 130 Cied., p. 10, 2007.

SANTOS, M. DAS G. F. DOS; MANTILLA, S. P. S. Fluência Tecnológica na Visão dos Tutores e seus Desafios. Revista Brasileira de Aprendizagem Aberta e a Distância, v. 15, 2016.

SILVA, F. R. DA; CAMPOS, V. C. O Ensino a Distância ao Longo das Gerações. Dez Jul /PP. 127 - 135, 2016, p. 127-135, 2016.

VIEIRA, R. S. O Papel das Tecnologias da Informação e Comunicação na Educação a Distância: Um Estudo Sobre a Percepção do Professor/Tutor. Revista Brasileira de Aprendizagem Aberta e a Distância, v. 10, p. 65-70, 2011. 